\title{
Increasing and intensification of the technology of purification of natural gas by composite absorbents
}

\author{
Oybek Aripdjanov ${ }^{1}$ and Xurshida Tirkasheva ${ }^{1, *}$ \\ ${ }^{1}$ Tashkent chemical-technological institute, 32, Navoi Street, 700011, Tashkent, Uzbekistan
}

\begin{abstract}
Today, the urgent task is the synthesis of new nanostructured composite sorbents used for the complete utilization of various wastes of oil and gas refineries, improving the technology of processes for cleaning natural and tail exhaust gases from acidic impurities, increasing the stability of the physicochemical properties of sorbents and improving the environmental conditions for processing secondary absorbents oil and gas refineries. Recently, in the world in oil and gas processing industrial enterprises, the main attention has been focused on the search for methods for purifying natural and waste gas from organic compounds of sulfur, mercaptans, carbonyl sulfide (COS), carbon disulfide $\left(\mathrm{CS}_{2}\right)$ and sulfides (RSR), as well as the creation of new types of highly effective composite adsorbents for gas purification.
\end{abstract}

\section{Introduction}

Natural gas has already taken a firm place in providing the national economy with fuel and raw materials for petrochemicals. Today, the use of hydrocarbon gases (natural and oil), an environmentally friendly type of fossil fuel and chemical raw materials, accounts for more than $25 \%$ of the world consumption of all hydrocarbons.

In industry, in installations for the purification of acid gases, monoethanolamine (MEA), diethanolamine (DEA) and methyldiethanolamine (MDEA) are mainly used as an absorbent. MEA, DEA and MDEA are used at a concentration of $30-35 \%$ and the saturation point of these absorbents with acidic components $\left(\mathrm{H}_{2} \mathrm{~S}\right.$ and $\left.\mathrm{CO}_{2}\right)$ is $0.350 .55 \mathrm{~mol} / \mathrm{mol}$.

\section{Method}

During operation, alkanolamine absorbents undergo various thermochemical transformations (degradation) upon contact with $\mathrm{H}_{2} \mathrm{~S}, \mathrm{CO}_{2}$ and other acidic impurities of natural gas. The largest number of studies on this problem is devoted LTSto monoethanolamine (MEEA), significantly less - diethanolamine (DEA) and just a few works of methyldiethanolamine (MDEA) and mixed absorbents - MDEA+ MMEA and MDEA+DEA, MDEA+HMTA (urotropine). Investigation of the thermochemical stability

\footnotetext{
*Corresponding author: khurti199@gmail.com
} 
of composite absorbents based on nitrogen-containing water-soluble polymers (ATSP) is not available in the literature. This circumstance is obviously connected with the fact that such absorbents have not yet found wide distribution abroad.

\section{Results}

The quality of composite solutions of absorbents determines not only the quality of gas cleaning, but also the loss of amines, their corrosive properties. In this connection, in this paper, the results of studies on this problem are presented.

The proposed compositional absorbent based on MDEA and DEA is prepared as follows: in a $20-25 \%$ aqueous solution of MDEA and DEA, a $0.1-10 \%$ mixture of a nitrogen-containing water-soluble polymer (AVRP) at $50-60{ }^{\circ} \mathrm{C}$ is mixed in a stirred tank reactor for 20-30 minutes, after passing through the filter, the absorbent is dosed into the absorption unit for purifying natural gas from hydrogen sulphide. Laboratory conditions for the purification of gases from $\mathrm{H}_{2} \mathrm{~S}$ and $\mathrm{CO}_{2}$ using a composite absorbent based on nitrogen-containing GRP established that the absorption capacity for acidic gas components will increase by $0.1-0.2 \mathrm{~mol} / \mathrm{mol}$, the foaming decreases comparatively $(\mathrm{H}=0.6-1,4 \mathrm{~cm})$, the lifetime of the foam $(0.5-1.0 \mathrm{sec})$, and other physicochemical parameters of the purification process. The initial absorption rate of $\mathrm{H}_{2} \mathrm{~S}$ is almost twice as large as that of $\mathrm{CO}_{2}$. Thus, this fact confirms that high selectivity for $\mathrm{H}_{2} \mathrm{~S}$ is achieved in a solution of a composite absorbent at low saturation with an acid gas, the selectivity depends on the kinetics of the process. The conditions for regeneration of a solution saturated with acidic components with an activator-AIPP do not require additional process costs, and also the temperature of the process can be reduced by $8-12^{\circ} \mathrm{C}$, i.e. $120-130^{\circ} \mathrm{C}$.

The study of the kinetics of sulfur absorption was carried out by a change in the electrical conductivity of the absorber solution (Table 1)

Table 1. Mixing of the initial and discharge solutions (1:3) of AWSP samples.

\begin{tabular}{|c|c|c|c|c|c|c|}
\hline $\begin{array}{c}\text { The content of initial sample } \\
\text { AWSP in the mixture, \% }\end{array}$ & 100 & 80 & 60 & 40 & 20 & 0 \\
\hline $\begin{array}{c}\text { The content of the discharge } \\
\text { sample №4 in the mixture, \% }\end{array}$ & 0 & 20 & 40 & 60 & 80 & 100 \\
\hline Resistance of the mixture, Ohm & 6780 & 689 & 568 & 543 & 502 & 489 \\
\hline
\end{tabular}

As follows from the data given, the specific resistance of the aqueous solution of ATSP sharply decreases when a spent solution appears in the initial reagent. After the proportion of the spent solution in the starting reagent exceeds $20 \%$, the resistivity decreases more smoothly. In this regard, the resistivity index of the solution can serve as an indicator of the processing of the initial reagent during gas desulfurization.

Based on the study of the kinetics of sulfur absorption of a composite absorbent with the use of AVRP in small plants of gas processing plants, it was found that the main factors influencing the value of the specific consumption factor are the parameters that contribute to the increase in the phase contact surface of the gas and reagent, such as the viscosity of the AVRP, the height of the reaction zone, And the linear velocity of the gas, the residence time of the gas in the reaction zone. In connection with this, the thermochemical stability of the AWSP was studied (Table 2). 
Table 2. Quantity of products of thermochemical transformations of AWSP, MDEA, DEA in the presence of $\mathrm{H}_{2} \mathrm{~S}$ and $\mathrm{CO}_{2}\left(\mathrm{~T}=85^{\circ} \mathrm{C}, \tau=180\right.$ hour $)$.

\begin{tabular}{|l|c|c|c|}
\hline \multirow{2}{*}{ Absorbents } & \multicolumn{3}{|c|}{$\begin{array}{c}\text { Quantity of products of transformations } \\
\text { mass \% in the presence: }\end{array}$} \\
\cline { 2 - 4 } & $\mathbf{H}_{2} \mathbf{S}$ & $\mathbf{C O}_{2}$ & $\begin{array}{c}\mathbf{H}_{2} \mathbf{S} / \mathbf{C O}_{2} \\
(\mathbf{2 : 1} \text { volume })\end{array}$ \\
\hline $30 \%$ solution of AWSP & Lack & Traces & Traces \\
\hline $\begin{array}{l}30 \% \text { solution } \\
\text { MDEA+DEA solution } \\
60+40 \%)\end{array}$ & Traces & 0.52 & 0.06 \\
\hline $\begin{array}{l}30 \% \text { Traces } \\
\text { AWSP+MDEA+DEA }\end{array}$ & The & 0.24 & 0.045 \\
\hline
\end{tabular}

The data obtained by gas chromatography on a capillary column with polyethylene glycol (PEG) and published data show that the temperature and concentration of $\mathrm{CO}_{2}$ have a decisive influence on the degradation of amines. And degradation is mainly subject to DEA and MIEA. Composite absorbent (AVRP+MDEA+DEA) practically does not undergo transformations. So at a temperature of $160^{\circ} \mathrm{C}$ and exposure in an atmosphere of $\mathrm{CO}_{2}$ of 94 hours in an absorber remains unconverted amine (\%): AWSP - 91\%, MDEA-90.9; DEA22.1; MIEA-11.4. In the absence of $\mathrm{CO}_{2}$ amines are stable. In the presence of one $\mathrm{H}_{2} \mathrm{~S}$, the amines do not degrade in the temperature range $80-160^{\circ} \mathrm{C}$. In the presence of $\mathrm{CO}_{2}$, the AWSP and MDEA are practically stable, whereas DEA and MIEA undergo significant transformations. The experimental sulfur content in the waste AWSP samples was $6-7 \%$ by weight. The IR spectra of the AVPP sample of the absorption bands are given in Table. 3 .

Table 3. Reference of bands of absorption of AWSP samples in the IR-spectrum.

\begin{tabular}{|c|c|c|c|c|c|}
\hline $\begin{array}{c}\text { Wave } \\
\text { number, } \\
\text { cm }^{-1}\end{array}$ & MEA & $\begin{array}{c}\mathrm{CH}_{2}=\mathrm{N}- \\
\mathrm{CH}_{2} \mathrm{CH}_{2} \mathrm{OH}\end{array}$ & $\mathrm{H}_{2} \mathrm{O}$ & $\begin{array}{c}\text { 1,3,5-three- } \\
\text { (2-oxyethyl) } \\
\text { hexahydrotriazine }\end{array}$ & Oxazolidine \\
\hline 3350 & $\begin{array}{l}v(\mathrm{O}-\mathrm{H}) \\
v(\mathrm{~N}-\mathrm{H})\end{array}$ & $v(\mathrm{O}-\mathrm{H})$ & $\begin{array}{c}v(\mathrm{O}- \\
\mathrm{H})\end{array}$ & $v(\mathrm{O}-\mathrm{H})$ & \\
\hline 2940 & $V$ as $(\mathrm{C}-\mathrm{H})$ & $V$ as $(\mathrm{C}-\mathrm{H})$ & & $V$ as $(\mathrm{C}-\mathrm{H})$ & $V$ as $(\mathrm{C}-\mathrm{H})$ \\
\hline 2878 & $v_{\mathrm{s}}(\mathrm{C}-\mathrm{H})$ & $v_{\mathrm{s}}(\mathrm{C}-\mathrm{H})$ & & $v_{\mathrm{s}}(\mathrm{C}-\mathrm{H})$ & $V{ }_{\mathrm{s}}(\mathrm{C}-\mathrm{H})$ \\
\hline 1660 & & $v_{\mathrm{s}}(\mathrm{C}=\mathrm{H})$ & & & \\
\hline 1600 & $\delta(\mathrm{N}-\mathrm{H})$ & & & & \\
\hline 1450 & $\delta\left(\mathrm{NH}_{2}\right)$ & $\delta\left(\mathrm{NH}_{2}\right)$ & & $\delta\left(\mathrm{NH}_{2}\right)$ & $\delta\left(\mathrm{NH}_{2}\right)$ \\
\hline 1406 & & $\delta(\mathrm{N}-\mathrm{H})$ act & & $\delta(\mathrm{N}-\mathrm{H})$ act & \\
\hline 1386 & & & & & \\
\hline 1350 & & $\delta(\mathrm{O}-\mathrm{H})$ & & & \\
\hline 1254 & & & & $v(\mathrm{O}-\mathrm{H})$ & $\mathrm{O}-\mathrm{C}-\mathrm{N}$ \\
\hline 1190 & $\delta(\mathrm{C}-\mathrm{H})$ & $\delta(\mathrm{C}-\mathrm{H})$ & & $v(\mathrm{O}-\mathrm{H})$ & O-C-N \\
\hline 1106 & & & & & $\mathrm{O}-\mathrm{C}-\mathrm{N}$ \\
\hline 1065 & $\delta(\mathrm{C}-\mathrm{O})$ & $v(\mathrm{C}-\mathrm{O})$ & & & \\
\hline 1035 & $\delta(\mathrm{C}-\mathrm{N})$ & & & & \\
\hline 960 & $\delta(\mathrm{N}-\mathrm{H})$ & & & & \\
\hline 930 & & $\begin{array}{c}\delta(\mathrm{O}-\mathrm{H}) \\
\delta \mathrm{CH}_{2}=\mathrm{N}\end{array}$ & & & \\
\hline
\end{tabular}


From the analysis of the IR spectrum, it can be assumed that the sample contains mainly 1,3,5-tris (2-hydroxyethyl) hexahydrotriazine and residual oxazolidines. Possible the presence of other compounds, the determination of which from the IR spectrum is difficult. The nature of their absorption bands indicates that the products formed are present in the polymer form, i.e. In the form of polycondensates.

In connection with the planned carrying out of pilot-industrial tests of the composite absorbent DEA+MDEA+AVRP, their corrosion aggressiveness was investigated.

The experiments were carried out in glass ampoules and autoclaves according to the procedure [1-4]. The use of ampoules allowed obtaining preliminary information with limited time and reagents, and autoclaves - information close to real conditions.

The results of the investigations are shown in Fig. 2,3 and in Table 4 (experiments in ampoules), as well as in table 4 and in fig. 4 (experiments in autoclaves). Analysis of the data obtained in ampoules shows that the corrosion rate of st.10 in the absorbentsDEA+MDEA, MDEA+DEA is higher if the absorbent is saturated with one $\mathrm{H}_{2} \mathrm{~S}$, than in the case of saturation with one $\mathrm{CO}_{2}$ (fig. 1.2). In the presence of $\mathrm{H}_{2} \mathrm{~S}$ and $\mathrm{CO}_{2}$, the maximum corrosion rate was observed at the ratio $\mathrm{H}_{2} \mathrm{~S} / \mathrm{CO}_{2}=(1.5-4)$ : 1 . The addition of $10 \%$ AWP to this absorbent reduces the rate of corrosion of steel by 2 times, and the addition of $20 \% \sim 3$ times. In addition, the corrosive aggressiveness of the DEA+MDEA solution containing more than $40 \%$ MDEA increases. Stainless steel is practically not corroded. Addition of $1 \%$ by weight. Hexamethylenediamine to the MDEA+DEA absorbent $(60 \times 40 \%)$, which showed the highest corrosion rate of $12 \mathrm{GF}-1.0 \mathrm{~mm} /$ year steel, reduces it to $0.11-0.12 \mathrm{~mm} /$ year. This fact requires additional special research.

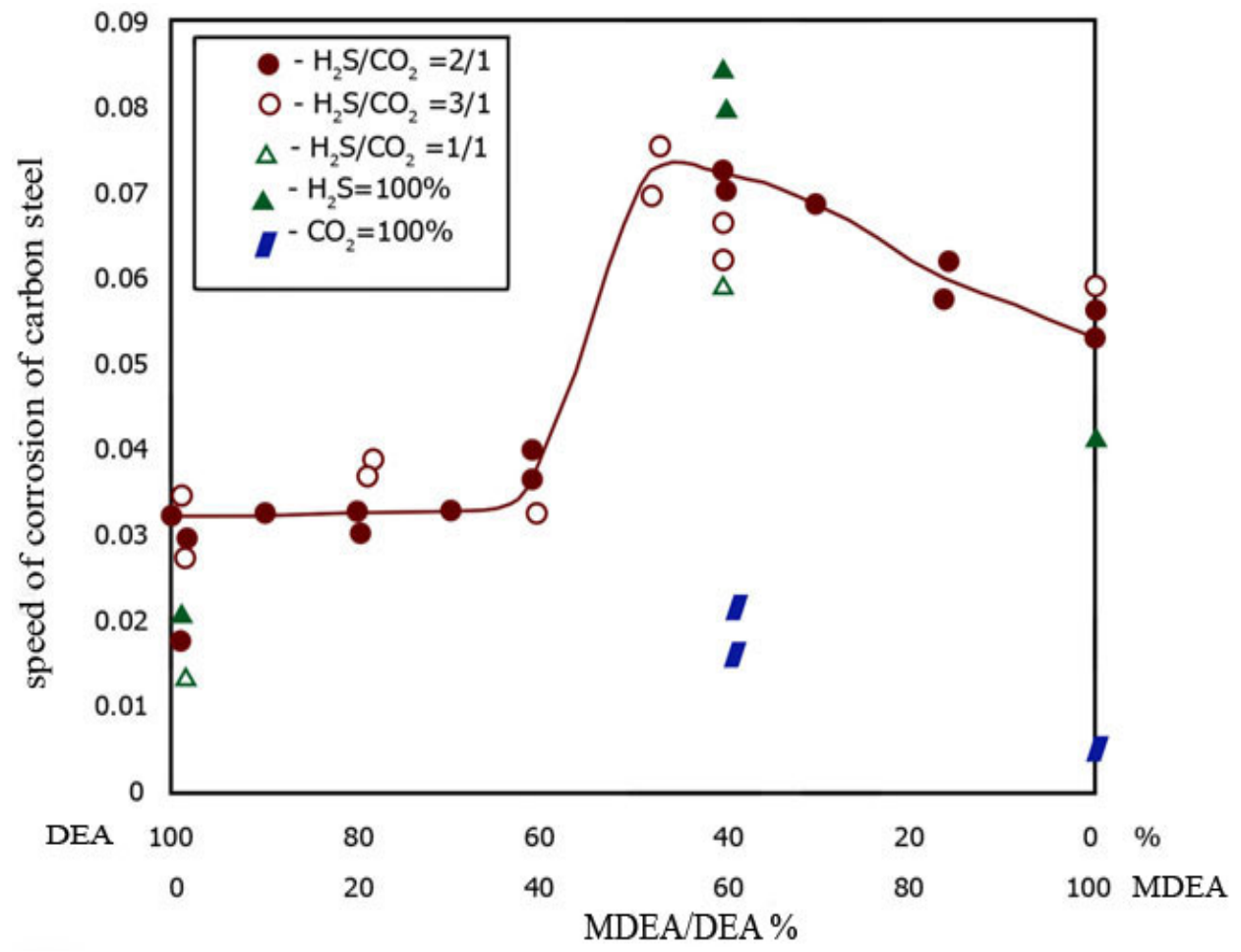

Fig. 1. Influence of ratio $\mathrm{H}_{2} \mathrm{~S} / \mathrm{CO}_{2}$ on rate of corrosion of carbon steel (Item $10 ; \mathrm{t}=80^{\circ} \mathrm{C} ; \alpha=0,6$ $\mathrm{mol} / \mathrm{mol} ; \tau^{\prime}=100$ hours). 


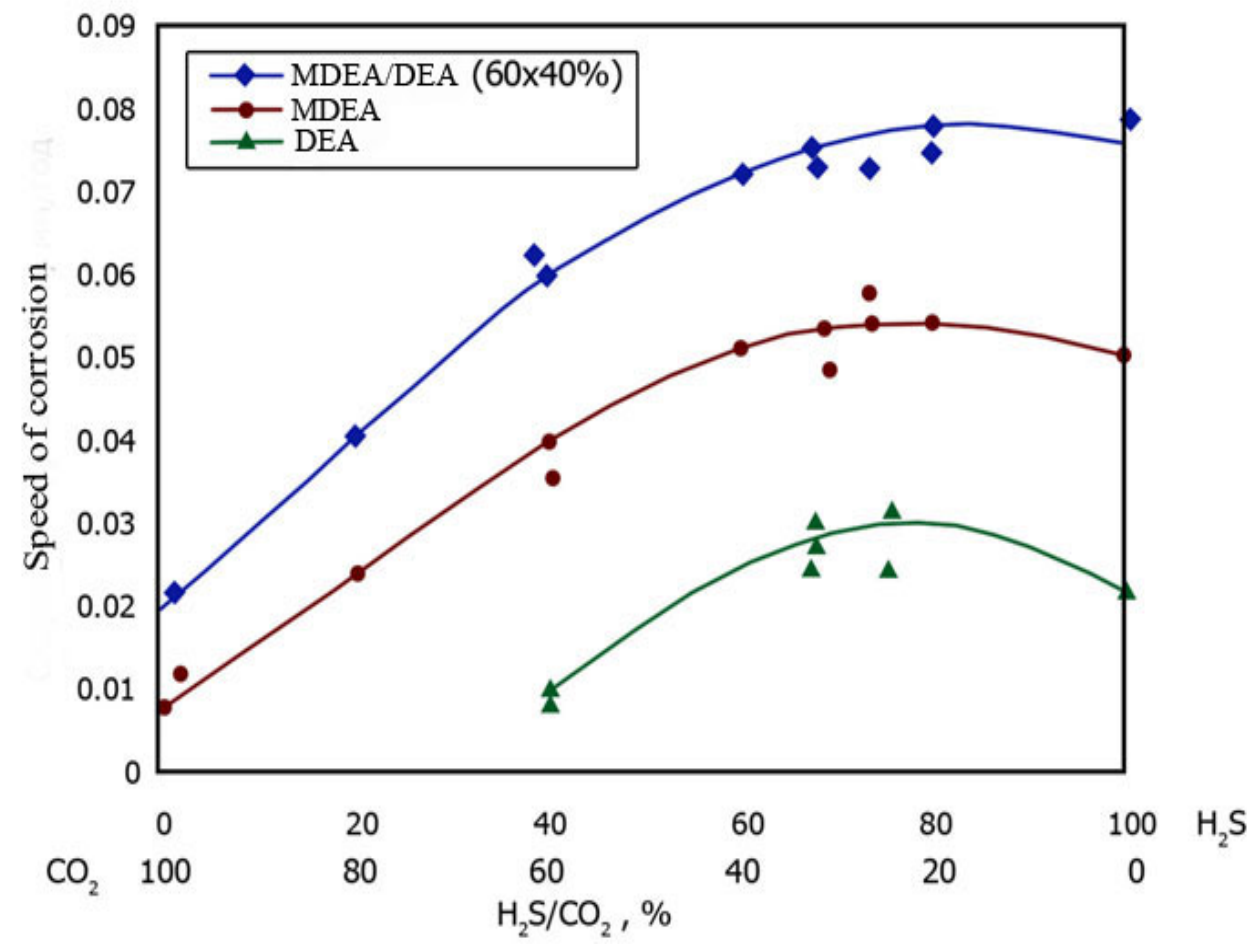

Fig. 2. Influence of ratio MDEA/DEA and $\mathrm{H}_{2} \mathrm{~S} / \mathrm{CO}_{2}$ on Corrosion rate of carbon steel $\left(\mathrm{t}=80^{\circ} \mathrm{C}, \alpha\right.$ $=0.6 \mathrm{~mol} / \mathrm{mol}, \tau=100$ hours).

Table 4. Rate of corrosion of carbon steel of mark $12 \mathrm{GF}$ on absorbent MDEA+DEA+AWSP (Experimentes in autoclaves) (Concentration of amines $40 \%$ by mass; temperature $90^{\circ} \mathrm{C}$; saturation of amines $\sim 1,0 \mathrm{~mol} / \mathrm{mol} ; \mathrm{H}_{2} \mathrm{~S} / \mathrm{CO}_{2}+2 ; 1, \mathrm{P}_{\text {work. }} \sim 5 \mathrm{MPa}$; $\mathrm{F}=360$ hours).

\begin{tabular}{|c|l|c|}
\hline № & \multicolumn{1}{|c|}{ Absorbent } & $\begin{array}{c}\text { Rate of corrosion of } \\
\text { carbon steel. mm/year }\end{array}$ \\
\hline 1. & DEA & 0.09 \\
\hline 2. & MDEA & 0.51 \\
\hline 3. & MDEA+DEA $(20 \times 80 \%)$ & 0.09 \\
\hline 4. & MDEA+DEA $(30 \times 70 \%)$ & 0.10 \\
\hline 5. & MDEA+DEA $(50 \times 50 \%)$ & 0.25 \\
\hline 6. & MDEA+DEA $(60 \times 40 \%)$ & 1.05 \\
\hline 7. & MDEA+DEA $(70 \times 30 \%)$ & 0.90 \\
\hline 8. & MDEA+DEA $(90 \times 10 \%)$ & 0.65 \\
\hline 9. & MDEA+DEA $(50 \times 50 \%)+10 \%$ ABPП & 0.10 \\
\hline 10. & MDEA+DEA $(50 \times 50 \%)+20 \%$ ABPП & 0.06 \\
\hline 11. & MDEA+DEA $(60 \times 40 \%)+1 \%$ hexamethylenediamine & 0.11 \\
\hline
\end{tabular}




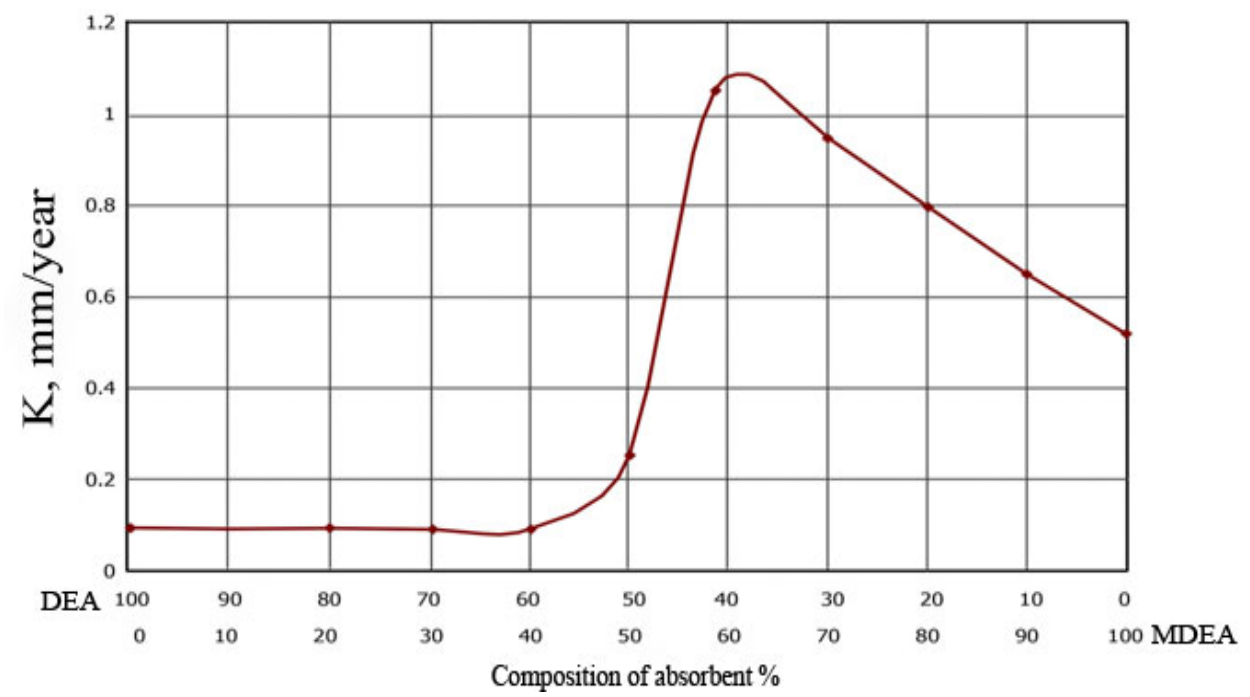

Fig. 3. Rate of corrosion (C) of carbon steel of mark 12 GF on absorbent MDEA+DEA $(\alpha \sim 1,0$ $\left.\mathrm{mol} / \mathrm{mol} ; \mathrm{t}=90^{\circ} \mathrm{C} ; \mathrm{P}=5 \mathrm{MPa} ; \mathrm{H}_{2} \mathrm{~S} / \mathrm{CO}_{2}=2: 1\right)$.

A sample of the composite absorbent DEA+MDEA+AWSP showed high efficiency in the post-treatment of gas from $\mathrm{H}_{2} \mathrm{~S}$ under the conditions of the Mubarak Gas Processing Plant (IGPP). During the experiments, no special positive properties of wood chips were observed as a nozzle for the contactor, and no convincing evidence of the negative effect of impurities in the gas on the efficiency of sulfur absorption of the AWSP was obtained. In table. 5. Some of these indices are obtained, calculated by the results of experiments.

Table 5. Regime parameters of experiments.

\begin{tabular}{|c|c|c|c|c|c|c|c|c|}
\hline \multirow{2}{*}{ } & \multicolumn{2}{|c|}{ Nozzle } & \multirow{2}{*}{ 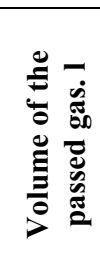 } & \multirow{2}{*}{ 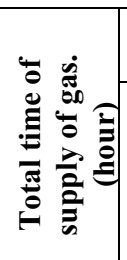 } & \multicolumn{2}{|c|}{$\begin{array}{c}\text { Content } \\
\mathrm{H}_{2} \text { S. g/nm }{ }^{3}\end{array}$} & \multirow{2}{*}{ 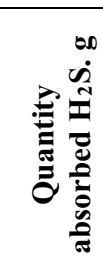 } & \multirow[b]{2}{*}{ 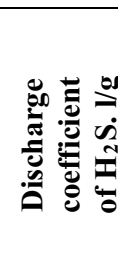 } \\
\hline & Type & $\begin{array}{c}\text { Height, } \\
\text { mm }\end{array}$ & & & 芯 & 흘 & & \\
\hline 1 & $\begin{array}{l}\text { Wood } \\
\text { chips }\end{array}$ & 200 & 50 & $\begin{array}{l}0.12 \\
\min \end{array}$ & 0.5 & 0.0140 & 0.024 & 2.05 \\
\hline 2 & $\begin{array}{l}\text { Wood } \\
\text { chips }\end{array}$ & 200 & 210 & 1 & 0.5 & 0.0013 & 0.1317 & 0.19 \\
\hline 3 & $\begin{array}{c}\text { Ceramic } \\
\text { beads }\end{array}$ & 200 & 800 & 5 & $\begin{array}{c}0.5- \\
0.4\end{array}$ & 0.00063 & 0.3336 & 0.075 \\
\hline 4 & $\begin{array}{c}\text { Ceramic } \\
\text { beads }\end{array}$ & 310 & 2110 & 28 & $\begin{array}{c}0.25- \\
0.3 \\
\end{array}$ & Lack & 0.5746 & 0.043 \\
\hline
\end{tabular}

\section{Conclusion}

The results of the experiments showed that the sample of the composite absorbent DEA+MDEA+AVRP even after 1.5 months of storage showed a stable desulfurization efficiency. All the experiments were carried out to the end, until the reagent was fully developed. As a result of the experiments, real consumption coefficients were obtained for the AWSP. When analyzing the results, it was found that the range of preferred consumption coefficients DEA+MDEA+AVRP $\left(0.015-0.0181 / \mathrm{g} \mathrm{H}_{2} \mathrm{~S}\right)$ is in the region of 
low linear gas velocities $(0.02-0.04 \mathrm{~m} / \mathrm{s})$, which corresponds to a sufficiently long residence time Gas in the reaction contact zone $(10-18 \mathrm{sec})$. The use of a composite absorbent on the basis of DEA and MDEA with the AWSP activator shows the following parameters in the technology for the purification of a little sulfur dioxide: the absorption capacity of the solution in $\mathrm{H} 2 \mathrm{~S}$ and $\mathrm{CO}_{2}$ is $0.4-0.5 \mathrm{~mol} / \mathrm{mol}$; Absorption temperature $-40-45^{\circ} \mathrm{C}$; The desorption temperature is $125-130^{\circ} \mathrm{C}$; The content of acidic components in the regenerated solution is $-0.006-0.01 \%$; The content of acidic components in purified gas is 0.0009 $0.0018 \%$.

\section{References}

1. O.Yu. Aripdjanov, Sh.P. Nurillaev, S.M. Turobjonov, Jiujang Petroleum \& Chemical Factory, China Petroleum \& Chemical Co. 4, 14-19 (2013)

2. G.K. Zibert, E.P. Zaparodjets, I.M. Vallilullin, Treatment and processing of hydrocarbon gases and condensed fluid. Technology and equipment. Instructional manual (Nedra, M., 2008)

3. V.V. Nikolaev, N.B. Busigina, I.G. Busigin, Basic processes of physical and physicochemical processing of gas (Nedra, M., 1998) 